\title{
DIAKRONIKA
}

Vol. 18 No. 1 Th. 2018 p: 1-17

ISSN: 1411-1764 (Print) | 2620-9446 (Online)

http://diakronika.ppj.unp.ac.id

\section{Invasi Yunani Ke Persia Sebagai Bukti Kebangkitan Kebudayaan Hellenis}

\author{
Anisa Septianingrum \\ anisa.septianingrum@fkip.unila.ac.id \\ Universitas Lampung
}

\begin{abstract}
Persia and Greece have engaged in a complicated relationship with war in the expansion of the territory. Persia was superior first because it was able to form strong empires and conquer cities around Asia and several cities in Europe. Greece managed to get rid of Persia, but it did not last long. Greece in ancient times consisted of many policies that competed with each other. The most famous policies of that period were Athens and Sparta. Both have advantages compared to other policies scattered in Greece. However, Athens and Sparta are two policies that compete with their respective strengths, causing disputes. Persia at that time had established good relations with Athens and Sparta. Persia found great opportunities to control Greece in the event of a war between Athens and Sparta. Persian interference in Greece was unavoidable which led to the Peloponnesian War which resulted in the conquest of Persia over Greece. Greece's downfall under the conquest of Persia did not last long. A unifying figure emerged in Greece that was able to embrace all policies and become the greatest king in history who had a vast conquest, both in the West and East. Alexander The Great was a king from the Kingdom of Macedonia in Greece who was able to unite all policies. Alexander invaded Persia to spread Hellenic culture.
\end{abstract}

Keywords: Invasion, Greece, Persia, Hellenic Culture

\section{Abstrak}

Persia dan Yunani telah terlibat hubungan yang rumit dengan adanya perang dalam perluasan wilayah. Persia sempat unggul lebih dulu karena mampu membentuk imperium yang kuat dan menaklukkan kota-kota di sekitar Asia dan beberapa kota di Eropa. Yunani sempat berhasil mengenyahkan Persia, tetapi tidak berlangsung lama. Yunani di masa kuno terdiri dari banyak polis-polis yang saling bersaing satu dengan lainnya. Polis yang paling terkenal pada masa itu adalah Athena dan Sparta. Keduanya memiliki keunggulan dibandingkan dengan polis-polis lain yang tersebar di Yunani. Namun Athena dan Sparta merupakan dua polis yang bersaing dengan kelebihan masing-masing sehingga menimbulkan perselisihan. Persia pada masa itu telah menjalin hubungan baik dengan Athena maupun Sparta. Persia menemukan peluang besar untuk menguasai Yunani jika terjadi perang antara Athena dan Sparta. Campur tangan Persia di Yunani tidak dapat dihindari sehingga menimbulkan Perang Peloponnesia yang berakibat penaklukan Persia atas Yunani. Keterpurukan Yunani di bawah penaklukan Persia tidak berlangsung lama. Muncullah tokoh pemersatu di 
Yunani yang mampu merangkul semua polis dan menjadi raja terbesar sepanjang sejarah yang mempunyai daerah taklukan luas, baik di wilayah Barat maupun Timur. Alexander The Great adalah seorang raja dari Kerajaan Makedonia di Yunani yang mampu mempersatukan semua polis. Alexander melakukan invasi ke wilayah Persia untuk menyebarkan kebudayaan Hellenis.

Kata kunci: Invasi, Yunani, Persia, Kebudayaan Hellenis

cc) (i) (?) This work is licensed under the Creative Commons Attribution-Share Alike 4.0 International License.

\section{Pendahuluan}

Semenjak zaman kuno, Yunani dan Persia telah menjalin hubungan diplomatik. Dinasti Achaeminiyah yang berkuasa lama di Persia dengan pergantian raja selama bertahun-tahun pernah mencapai prestasi gemilang. Salah satu prestasi yang mengagumkan adalah kenyataan bahwa daerah taklukan Persia pernah mencapai kawasan yang jauh hingga sampai ke Yunani yang secara geografis masuk di wilayah Benua Eropa. Yunani waktu itu telah memiliki sistem pemerintahan sendiri yang terbagi ke dalam beberapa Negara Kota yang disebut Polis. Negara Kota memiliki ciri khas masing-masing tergantung pada kelompok masyarakat yang mengusungnya.

Dinasti Achaeminiyah di Persia memiliki ambisi besar untuk bisa menaklukkan daerah lain yang berpotensi baik dari sisi sumber daya alam maupun sumber daya manusianya. Maka bukan hal yang mengherankan jika Yunani menjadi tempat incaran yang potensial. Strategi untuk bisa mengambil alih kawasan lain tidak dilakukan dengan jalan perang saja. Beberapa praktik ikut campur dalam urusan intern polis-polis di Yunani juga dilakukan. Strategi ini cukup membuahkan hasil yang menguntungkan karena dua polis di Yunani menjadi terlibat konflik. Setelah adanya pertikaian yang berkelanjutan, muncul peluang dan celah bagi Persia untuk menakhlukkan wilayah Yunani yang sangat tidak stabil dari segi politik, pemerintahan, dan lain sebagainya. Kelalaian dalam menjaga stabilitas intern membuka kesempatan bagi bangsa asing yang telah lama menginginkan Yunani.

Perang antar polis tidak dapat dihindarkan. Musuh semakin senang dengan keadaan yang terjadi di Yunani. Akibatnya Persia berhasil menjadikan Yunani sebagai daerah taklukannya. Keberhasilan yang didapatkan oleh Persia adalah kelalaian dari polis-polis di Yunani. Perang Peloponnesia menimbulkan kerugian yang besar bagi bangsa Yunani. Sparta dan Athena merupakan polis yang kuat tetapi kurang berhati-hati dalam mengambil kebijakan. Kecerobohan itulah yang membuat bangsa Yunani jatuh dalam dominasi pihak asing. 
Persia merupakan salah satu elemen peradaban Timur yang berlokasi di Iran sekarang. Iran terletak di daerah lembah Mesopotamia, sebuah kawasan dengan peradaban yang maju pada saat itu. Oleh kebanyakan ahli daerah tersebut dikenal dengan "the cradle of civilization" atau lahirnya peradaban. Sementara istilah lain yang sering disebutkan antara lain "the fertile crescent untuk menyebut daerah yang subur, sementara julukan "the Levant" menunjuk kepada arah (dimana bangsa Arab menyebut masyriq). Imperium Persia didirikan oleh Cyrus pada 549 BC. Setelah berhasil mendirikan kekaisaran, Cyrus berusaha untuk menguasai wilayah-wilayah di sekitarnya. Pertama kali bangsa Persia mengalahkan Chaldea, kemudian memperluas wilayahnya dengan menyerang Babylonia. Perluasan wilayah dilanjutkan oleh Cambyses dengan menganeksasi Mesir (Stewart, 1995).

Raja yang terkenal dari Persia ialah Darius I. Garis keturunan Darius I berasal dari salah satu anggota kerajaan Achaeminiyah. Buyutnya bernama Ariaramnes yang berkuasa di Persia bersama-sama dengan saudaranya Cyrus I. Anak Ariaramnes, Arsames, dan cucu laki-lakinya, Hystaspes tidak menjadi raja di Persia karena kekuasaan kerajaan disatukan di tangan Cambyses I melalui Cyaxares. Namun, Hystaspes merupakan seorang pangeran yang penting dan menjadi gubernur Persia. Darius mewarisi sifat-sifat Cyrus The Great, yaitu pemimpin berkepribadian kuat dan dinamis (Sudrajat \& Miftahuddin, 2008)

Darius melebarkan daerah kekuasaannya dengan melakukan penaklukan ke Benua Eropa. Kontak fisik terjadi pada tahun 500 SM antara polis-polis (negara kota) di Yunani dengan penguasa Persia. Invasi ke Yunani membutuhkan strategi perang yang matang serta diplomasi politik yang cerdas. Kepemimpinan Darius I yang diwarnai dengan berbagai perang untuk menguasai kota-kota penting dibantu oleh menantunya yang bernama Mardonius. Serangan Darius ke polis lonia membuat polis besar lainnya seperti Athena yang mengusung pemerintahan demokratis tergerak untuk membantu lonia yang notabennya masuk ke dalam kawasan Yunani.

Perang Peloponnesia menjadi pelajaran yang sangat berharga bagi Yunani agar bisa bersatu dan tidak terpecah belah kembali. Kesadaran bangsa Yunani tidak datang begitu saja. Alexander, seorang raja dari Makedonia merupakan tokoh inti yang mampu melakukan penyatuan dan memperkuat kedudukan Yunani dalam kancah internasional. Kebetulan raja-raja yang memerintah di Achaeminiyah sudah tidak kuat lagi seperti dulu. Kekuasaan Persia menunjukkan penurunan dratis. Seperti matahari yang timbul tenggelam di pagi dan sore hari. Masa kejayaan Persia sedikit demi sedikit mulai meredup hingga akhirnya padam. Darius III tidak mampu menghadapi serangan dari bangsa Yunani di bawah kepemimpinan Alexander The Great. 
Antara tahun 334 dan 330 SM, Alexander The Great menyempurnakan penaklukannya atas seluruh wilayah kerajaan Achaeminiyah. Pembakaran yang dilakukan oleh Alexander terhadap istana kerajaan di Persepolis pada tahun 330 SM menyimbolkan berakhirnya orde lama dan dimulailah peradaban Yunani di Asia Barat. Orang-orang Yunani dan tentara Makedonia menempati sebagian besar wilayah Mesopotamia dan Iran. Alexander menyarankan kepada para tentaranya untuk melakukan pernikahan silang dan mengembangkan kebudayaan Yunani. Meskipun demikian, ia masih mempertahankan sebagian besar struktur administrasi dinasti Achaeminiyah, memperkenalkan unsur-unsur oriental, dan lembaga politik Yunani (Sudrajat \& Miftahuddin, 2008)

Demi memperkuat kedudukannya di Persia, Alexander menikahi seorang putri cantik asal Persia yang bernama Roxmana. Penguatan kekuasaan dengan perkawinan politik sudah terjadi dalam kurun waktu yang lama. Hal itu bertujuan agar rakyat dari daerah taklukan lebih mudah dikendalikan. Jika ada simbol pendamping pemimpin baru yang asli dari sebuah tempat pasti penduduknya menjadi lebih segan dari pada dipimpin oleh seseorang yang sama sekali asing.

Kejayaan Persia yang tadinya hampir menguasai kerajaan-kerajaan besar di sekitar kawasan Asia Barat ditumbangkan oleh musuhnya sejak lama. Dari masa ke masa perang antara Yunani dan Persia tidak bisa dihindari lagi. Invasi akan memberikan keuntungan besar bagi Yunani mengingat Persia yang tadinya adalah imperium besar dengan daerah kekuasaan yang luas mampu ditaklukkan atas kerja keras yang menguras energi.

Invasi berarti menguasai wilayah dan bisa sekaligus memperkenalkan budaya baru bagi pihak yang menang dalam perang. Kebudayaan yang diusung oleh orang-orang Yunani di bawah kepemimpinan Alexander the Great adalah kebudayaan Hellenis. Tentunya kebudayaan ini sangat berbeda dengan adat yang sudah lama berkembang di Persia. Masyarakat Persia harus mempelajari budaya asing sekaligus merasakan sistem pemerintahan baru dari Yunani.

Permasalahan yang sering muncul adalah penyesuaian masyarakat dengan adanya pembaharuan kebudayaan. Mengingat pada masa sebelumnya orangorang Persia hidup di bawah kepemimpinan pribumi dan hidup merdeka. Kedatangan pasukan tentara Yunani di bawah komando Alexander membawa permasalahan yang rumit bagi penduduk Persia. Penduduk Persia menghadapi tekanan saat perang berlangsung hingga kekalahan yang berujung invasi bangsa Yunani dan penyebaran kebudayaan Hellenis. 
Bangsa Yunani Kuno memiliki peradaban yang tinggi. Peradaban bangsa Yunani ini kemudian dikembangkan oleh bangsa Barat. Peradaban bangsa Yunani ini meliputi kebudayaan Kreta, Polis, sistem kepercayaan, dan hasilhasil kebudayaan. Yunani dikelilingi oleh Laut Aegea dan Laut Lonea. Yunani terdiri atas dua bagian, yaitu Yunani Daratan dan Yunani Kepulauan. Wilayah daratan terdiri atas beberapa pegunungan, daerahnya terpecah-pecah, pantainya berteluk-teluk, dan airnya tenang. Oleh karena itu, Yunani sangat cocok untuk pelabuhan. Sementara itu, daerah kepulauan berada di Laut Aegea.Daerah ini terdiri dari pulau-pulau. Di antara pulau-pulau tersebut terdapat Pulau Kreta. Pulau Kreta adalah awal perkembangan kebudayaan di Yunani dan Romawi (Sondranika, 2015)

Yunani masa kuno diisi oleh peradaban Pulau Kreta. Peradaban tersebut adalah peradaban Minoa yang terbagi dalam tiga periode, yaitu Minoa awal yang berakhir pada 2300 SM, Minoa madya berkembang mulai 2300 SM1600 SM, dan Minoa akhir mulai tahun 1600 SM-1100 SM. Perkembangan tentang peradaban Minoa awalnya hanya diketahui dari legenda-legenda yang diceritakan secara turun-temurun dari satu generasi ke generasi berikutnya. Namun, seiring berjalannya waktu banyak reruntuhan bahkan tulisan dalam lempengan dengan huruf Aegea yang berhasil ditemukan (Rapar, 1998).

Peninggalan berupa situs lebih dari seratus kota, keramik-keramik, jalurjalur jalan yang sudah diperkeras, dan ratusan lempengan yang memuat tulisan telah ditemukan pada periode selanjutnya. Jenis temuan yang populer adalah istana di Knossus yang paling tidak terdiri dari dua tingkat dan menempati satu areal yang sama dengan satu blok kota. Istana Knosuss merupakan miniatur sebuah kota yang memiliki sarana pengairan, selokanselokan, tanah lapang yang dipergunakan untuk pesta dansa, gulat, dan olahraga-olahraga lainnya. Temuan-temuan tim arkeolog mengindikasikan bahwa peradaban Pulau Kreta tidak kalah jika dibandingkan dengan peradaban Mesir kuno (Rapar, 1998).

Kejayaan kebudayaan Kreta mencapai puncaknya pada masa Raja Minos (periode Minoan). Pada waktu itu sang raja menguasai Laut Aegea hingga Swedia. Pemimpin tersebut mampu menyatukan dataran Eropa, Asia, dan Afrika. Kerajaan Minos telah memanfaatkan letak geografisnya yang strategis, mengembangkan bidang pelayaran dan memperkuat armada laut. Armada ini merupakan angkatan laut pertama di dunia. Kehebatan armada maritim kerajaan Minos telah berhasil membuat kerajaan ini membina hubungan dagang yang baik dengan Mesir, Syria, Babylon, Asia Kecil, dan lain-lain, bahkan menjadi negara yang menguasai lautan. Berbagai kepulauan di Laut Aegea ramai-ramai membina hubungan dengan pertukaran duta negara, 
Swedia bahkan menyetor upeti pada Kerajaan Minos. Bangsa Minos ini akhirnya hancur karena bencana alam(Sondranika, 2015).

Bangsa Yunani Kuno terdiri atas berbagai suku bangsa. Mereka mendiami wilayah yang disebut "negara kota" atau "polis." City State yaitu sebuah kota yang terbentang sebagai pusat kota dengan daerah pedesaan di sekitarnya. Setiap negara kota didiami oleh masyarakat merdeka dengan hak pemerintahan sendiri. Polis pada hakikatnya adalah sebuah negara kecil yang merdeka. Di Yunani terdapat tiga polis besar dan kuat yaitu Athena, Sparta, dan Thebe (Sondranika, 2015).

Warga yang tinggal di suatu polis disebut dengan polites. Seorang polites mempunyai hak untuk berdebat dan hak untuk memberikan suara, sebuah keputusan yang mempengaruhi jalannya pemerintahan polis dan warga lainnya. Munculnya polis sebagai sebuah entitas politik terjadi pada tahun 800 hingga 600 SM. Di antara banyak polis yang muncul, Sparta dan Athena merupakan dua buah polis yang mewakili karakteristik polis-polis lainnya. Athena dan Sparta juga tumbuh menjadi dua buah kekuatan politik mendominasi sejarah Yunani (Sudrajat, 2010).

Sparta terletak di atas Padang Lakedaemon yang terkurung daratan. Penduduknya ialah kaum bangsawan Doria. Demi mengamankan diri orang Sparta membentuk Falanx Hoplite yang terdiri dari barisan rapat, 8 orang ke samping, 8 orang ke belakang sedangkan Hoplite adalah prajurit infantri bersenjata berat. Perlengkapan pasukan perang terbuat dari perunggu dan besi (Ashadi, 2016). Platfrom politik dan pemerintahan polis Sparta bersifat oligarki-militeristik. Pemerintahan Sparta dipimpin oleh dua orang raja yang kurang memiliki wewenang dalam bidang pemerintahan. Akan tetapi raja mengepalai angkatan perang dan berperan sebagai pendeta tertinggi dalam ritual keagamaan. Saat keadaan darurat perang, raja memiliki kekuasaan yang mutlak. Meskipun memiliki raja, tetapi Sparta tetaplah sebuah polis yang sama seperti negara kota di sekitarnya yang terletak di Yunani (Stewart, 1995).

Konstitusi orang-orang Sparta seluruhnya dibuat oleh Lykurgos, seorang pembuat hukum yang hebat dan misterius. Tanah diolah para Helot, penggarap tanah memberikan separoh panen mereka kepada bangsawan Sparta. Orang Sparta hidup sederhana. Penggunaan logam mulia dilarang. Orang Sparta mengutamakan kebugaran jasmani. Anak-anak yang sakit ditelantarkan, sedangkan yang sehat tidak dimanjakan. Atlet-atlet terbaik dikirim ke Olimpiade di Elis. Anak-anak Sparta meninggalkan rumah dan mulai hidup di asrama sejak usia 7 tahun. Memasuki umur 12 tahun, dia menyerahkan seluruh bajunya dan hanya diberi satu jubah. Beratnya ujian harus dilalui pada usia 16 tahun dimana anak-anak Sparta pergi sendirian 
selama beberapa minggu di alam bebas yang tentunya penuh dengan tantangan, seperti serangan hewan buas, bertahan dalam segala cuaca, mendapat anjuran untuk merampok kaum Helot. Namun, jika mereka gagal menunaikan tugasnya akan diberi hukuman cambuk sampai mati (Ashadi, 2016).

Kerasnya ajaran hidup yang harus ditempuh oleh penduduk Sparta membuat mereka dikenal sebagai orang-orang yang tangguh dan ditakuti oleh polis-polis lainnya. Kekuatan militernya sangat kuat, apalagi jika menghadapi serangan dari bangsa-bangsa lainnya yang mengancam keamanan masyarakatnya. Wanita di sana juga memiliki hak yang leluasa untuk berkecimpung di bidang pemerintahan dan politik. Hal itu berlaku jika para laki-laki yang biasanya memegang posisi penting sedang pergi keluar atau pun terlibat dalam perang yang menyita banyak waktu. Maka dari itu sistem politik di Sparta tetap berjalan sebagaimana mestinya.

Kunci utama kesuksesan yang dapat disandang oleh Sparta di bidang kemiliteran adalah disiplin tinggi yang diterapkan bagi penduduk dari mereka kecil hingga tua. Hukum yang telah disepakati bersama dilakukan secara benar dan ada sebuah konsekuensi bagi siapa saja yang berani melanggar aturan bersama. Sparta menjadi kuat dan disegani oleh polis lainnya. Penduduk Sparta rajin melakukan latihan fisik agar menjadikan mereka semakin kuat. Sebagai penyandang polis militer Sparta mempertahankan aturan yang berlaku dari nenek moyangnya.

Warga Athena jauh berbeda dengan Sparta. Athena memberikan jaminan kepada warganya dan menghapuskan perbudakan. Warga difokuskan untuk kemajuan seni, teknologi, dan filsafat. Athena merupakan polis yang menerapkan sistem demokrasi. Sistem itu diperkenalkan oleh Solon (638 SM559 SM). Dengan sistem itu, kekuasaan berada di tangan dewan rakyat. Pelaksanaan pemerintahan dilakukan oleh sembilan orang Archon yang setiap tahun diganti. Mereka diawasi oleh Aeropagus (Mahkamah Agung) yang para anggotanya berasal dari mantan anggota Archon. Athena menghasilkan banyak filsuf yang pemikirannya berpengaruh kuat pada kehidupan manusia hingga dewasa ini(Sondranika, 2015).

Masyarakat Athena harus berjuang untuk mencukupi kebutuhan hidup mereka karena wilayah tempat mereka hidup tanah kurang subur dan tidak cocok untuk tanaman pertanian. Kehidupan orang-orang Athena bertumpu pada sistem perdagangan. Meskipun jauh berbeda dengan Sparta yang mengagungkan kehidupan militer demi menunjang kelancaran dan keamanan, kegiatan perdagangan penduduk Athena memiliki angkatan laut. 
Athena merupakan salah satu city state yang menjadi icon kemajuan peradaban Yunani. Karakteristik budaya Yunani yang sampai saat ini menjadi icon budaya Barat adalah kebebasan dan demokrasi. Hal tersebut tergambar dalam pidatoLeotychides sesaat sebelum terjadi pertempuran di Mycale. Dalam hal ini Pericles menyatakan bahwa pemungutan suara, jaminan persamaan bagi warga, dan pengakuan atas perbedaan diantara individu merupakan pilar terpenting dalam peradaban Yunani. Sedemikian bangganya bangsa Athena dengan demokrasi, persamaan hak, dan pencapaian budayanya sehingga mereka menyebut bagian dunia yang didiami oleh masyarakat yang beradab dengan sebutan Oikoumene (Toynbee, 2004).

Konsentrasi penduduk Athena terfokus pada pengembangan seni dan ilmu pengetahuan. Pemimpin polis memberi perhatian yang besar terhadap pembangunan kuil, taman umum, dan tempat olah raga. Kemegahan arsitekturnya tidak diragukan lagi mengingat para seniman juga dilibatkan untuk mempercantik kota. Seni pembuat patung, pemahat, dan pelukispelukis diberi ruang untuk mempublikasikan hasil karya seni yang bernilai tinggi. Selain itu Athena juga melahirkan banyak tokoh penulis, pemikir dan para cendekiawan yang dikenal sebagai filsuf ternama dunia.

Ilmu pengetahuan yang berkembang di Yunani cukup populer karena banyak tokoh cendekiawan meneliti asal-muasal sesuatu secara mendetail. Perkembangan alam pikiran masyarakat berjalan beriringan dengan aliranaliran filsafat saat itu. Beberapa filsuf yang terkenal sebelum Socrates diantaranya: Thales, Anaximandros, Anaximenes, Herakleitos, Xenophanes, Parmenides, Zeno, Melissos, Pythagoras, Empedokles, Anaxagoras, Leukipos, Demokritos, Protagoras, Gorgias, Hippias, Prodikos, dan lain-lain.

Filsuf ternama dari Yunani periode kuno ada tiga yang hingga saat ini masih sering disebut-sebut dan digunakan hasil pemikarannya untuk mengembangkan ilmu-ilmu tertentu. Tokoh ternama pertama yang menjadi guru dari filsuf-filsuf berikutnya adalah Socrates. Socrates mencari dan mendalami ilmu pengetahuan dengan cara berdialog dengan siapa saja yang dia temui. Sebagai seorang filsuf yang mengedepankan kebijaksanaan, Socrates memperlihatkan budi pekerti yang luhur, seperti berkata jujur, hidup penuh kesederhanaan, berlaku adil terhadap siapa saja tanpa memandang ras ataupun status sosial, bersikap saleh dan lain sebagainya.

Pemikiran Socrates menghasilkan cara berpikir yang disebut induksi yaitu menyimpulkan pengetahuan yang sifatnya umum dengan berpangkal dari banyak pengetahuan tentang hal yang khusus (Bertens, 1975). Akhirnya Socrates menemukan apa yang disebut dengan definisi umum. Definisi umum bukan hal utama yang diperlukan bagi keperluan ilmu pengetahuan. Definisi 
umum tentang lingkaran misalnya, menjelaskan apakah hakekat lingkaran yang sebenarnya yang berlaku bagi tiap-tiap lingkaran, entah besar, entah kecil, entah di tempat ini, di tempat lain, pada masa lampau, pada masa kini ataupun di masa depan (Hadiwijono, 1980).

Murid Socrates yang juga menjadi filsuf ternama adalah Plato. Plato suka menuliskan hasil pemikirannya dalam sebuah karya. Orang-orang umum mengenal betapa cerdasnya Socrates juga melalui muridnya ini. Buku-buku fenomenal karya Plato beberapa mengisahkan tentang dialektika yang dilakukan oleh Socrates dengan orang-orang penting. Sebagai contoh adalah karya Plato yang berjudul Timaeus dan Critias, di dalamnya ada beberapa yang berisi tentang percakapan antara Socrates dengan seorang pendeta dari Mesir yang bernama Solon. Bahasan utama dalam dialog tersebut adalah kemegahan Atlantis. Solon memberikan info kepada Socrates bahwa di suatu negeri bernama Atlantis kehidupan berjalan dengan damai dan sejahtera. Atlantis dikelilingi oleh gunung berapi yang banyak, tanahnya sangat subur, terdapat emas, banyak gajah, memiliki dua musim, ilmu pengetahuan serta teknologi berkembang pesat dan tingkat peradabannya begitu tinggi.

Informasi tentang Atlantis memang masih terbatas. Namun, keberadaannya telah digambarkan dalam karya Plato. Dua orang yang melakukan percakapan benar-benar nyata dan cerita mengenai Atlantis memang secara turun-temurun diwariskan oleh leluhur kepada generasi penerusnya. Kebenaran dari tulisan Plato masih diselidiki oleh para ilmuan untuk mengetahui secara mendetail letak Atlantis yang sebenarnya. Jika masih ada sisa-sisa peradaban Atlantis yang tertinggal di bumi, maka penelitian tentang tingginya peradaban di masa lampau bisa terkuak.

Plato (427-347 SM) merupakan filsuf ternama dari Yunani yang lahir di Athena dan merupakan murid dari Socrates. la berasal dari kalangan kelas atas dari golongan aristokrasi yang memiliki wajah tampan dan mempesona. Secara fisik Plato sangat menarik didukung oleh asal keturunan orang terpandang yang membuatnya semakin disegani oleh banyak kalangan. Selain belajar penuh tentang banyak ilmu pengetahuan, Plato juga belajar menggambar, melukis, musik, puisi dan senam. Meskipun diajar oleh guruguru lainnya yang juga merupakan murid dari filsuf ternama, Plato tetap mengidolakan Socrates sebagai guru utamanya. Socrates digambarkan sebagai juru bahasa isi hati rakyat Athena yang tertindas oleh kekuasaan yang saling berganti (Muhammad Hatta, 1986).

Perhatian Plato di bidang pendidikan sangat tinggi. Ilmu bukan apa-apa bila tidak disampaikan kepada sesama manusia. Jiwa Plato tergugah untuk mendirikan tempat khusus bagi anak-anak yang ingin mempelajari ilmu 
pengetahuan. Plato akhirnya membuka sebuah sekolah dengan sebutan Akademia. Pengajaran yang dilakukan memicu peserta didiknya untuk berkembang menjadi pribadi dengan sikap kritis. Palto membuka diskusi tanya jawab sehingga pembelajaran bukan bersifat satu arah.

Filsafat Plato bertumpu pada ajarannya tentang ide karena ia percaya bahwa ide merupakan realitas yang sebenarnya dari segala sesuatu yang ada dan dapat dikenal melalui panca indra. Manusia, kupu-kupu, kucing, tumbuhtumbuhan, akan mati, tetapi ide tentang kupu-kupu, bunga, dan lain-lainnya tidak akan pernah berubah. Ide adalah realitas yang sebenarnya atau keberadaan yang sesungguhnya, maka bagi Plato ide bukanlah sekedar gagasan atau gambaran yang hanya berada di dalam pemikiran manusia. Ide bukanlah sesuatu yang subjektif yang tercipta oleh daya pikir manusia dan oleh sebab itu keberadaan ide bergantung pada daya pikir manusia. Sebagai realitas yang sebenarnya, menurut Plato ide bersifat objektif (Rapar, 1998).

Pandangan Plato mengenai negara yang dijadikan pokok masalah utama ialah keselamatan orang yang diperintah, bukan keselamatan orang yang memerintah. Orang-orang yang duduk dalam jabatan pemerintahan memerlukan pendidikan yang melebihi golongan-golongan lain. Mereka harus mempelajari kesenian, persajakan, musik, dan lain sebagainya. Mereka wajib belajar filsafat hingga umur tiga puluh tahun yang meliputi segala cabang ilmu pasti. Tugas negarawan adalah menciptakan keselarasan antara semua keahlian. Negarawan sejati akan menjaga keutuhan negara dan tidak melakukan tindakan yang bisa memicu perpecahan yang diakibatkan oleh keberagaman. Kerja keras negarawan adalah berjuang untuk kesejahteraan rakyat dan mengaplikasikan segala ilmu yang telah dipelajari untuk membangun negaranya ke arah yang lebih baik dan maju (Septianingrum, 2017).

Filsuf ketiga dikenal dengan nama Aristoteles. Bagi Yunani, filsuf satu ini memberikan kontribusi yang besar dalam membentuk karakter pemimpin. Bekas murid Plato yang juga tertarik mendalami berbagai macam ilmu pengetahuan mendapat kesempatan untuk menjadi guru bagi putra mahkota Kerajaan Makedonia anak dari Raja Philip II. Berkat kompetensi dan keahliannya dalam mengajar anak raja, Aristoteles memberikan pandangan yang luas kepada muridnya, yaitu Alexander The Great. Ilmu tentang pemerintahan, cara berpolitik, dan pandangan tentang Yunani didapatkan Alexander dari filsuf ternama satu ini.

Latar belakang Aristoteles bisa menjadi guru bagi putra mahkota dikarenakan ayahnya merupakan dokter yang bekerja untuk raja Makedonia. Ilmu yang dikuasai oleh ayahnya mempengaruhi ketertarikan Aristoteles 
terhadap ilmu-ilmu eksak seperti biologi dan matematika. Tempat menimba ilmu pengetahuan Aristoteles adalah Akademia. Semacam sekolah formal seperti yang ada di jaman modern dengan sistem pembelajaran aktif dimana siswa dan guru bisa saling berinteraksi dengan melakukan dialog. Apalagi Akademia digagas oleh orang-orang yang kompeten di bidang penelitian dan pengembangan ilmu pengetahuan.

Logika formal merupakan hasil temuan Aristoteles yang dirintis oleh Kaum Sofis dan dialektika yang umum digunakan untuk menimbang-nimbang pada masa hidup Plato. Inti pokok logika Aristoteles ialah ajarannya mengenai penalaran dan pembuktian. Baginya penalaran pertama-tama berupa silogisme yang di dalamnya berdasarkan dua buah tanggapan orang yang menyimpulkan tahapan ketiga. Perlu pemahaman tentang hakekat tanggapan. Banyak jenis-jenis tanggapan, ada yang menguatkan dan juga ada yang melemahkan (Delfgauw, 1992).

Ajaran Aristoteles yang terpenting adalah mengenai nyawa, terutama dalam hal ini dapat diikuti secara jelas perkembangan ajarannya yang bertolak dari pendirian Plato sampai pada pendiriannya sendiri. Berangkat dari dualisme ajaran Plato, melalui ajaran mekanisme yang dianutnya sementara, Aristoteles tiba pada kenyataan adanya kesatuan hakiki antara nyawa dengan tubuh. Menurut Aristoteles nyawa adalah bentuk tubuh dan karena bersama dengan tubuh merupakan suatu kesatuan tidak terpisahkan. Adakalanya nyawa sebagai asas hidup bersifat fana, maka Aristoteles berkeyakinan mengenai keabadian jiwa manusia (Delfgauw, 1992).

Aristoteles memiliki pandangan bahwa ilmu pengetahuan bertugas mencari penyebab-penyebab objek yang diselidiki. Kekurangan utama para filsuf-filsuf terdahulu tentang alam adalah tidak menyelidiki semua sebab. Menurut Aristoteles setiap kejadian mempunyai empat penyebab yang harus dijawab semuanya. Hal itu berlaku untuk kejadian alam maupun bagi kejadian yang disebabkan oleh manusia (Bertens, 1975).

Invasi yang dilakukan Yunani kepada Persia menyimpan alasan yang kuat. Ketika Persia masih dipimpin oleh Darius Agung, daerah kekuasaannya luas. Bahkan tentara Persia menyerang Yunani berkali-kali. Motif yang terkandung pada setiap penyerangan pasti tidak jauh dari motif politik dan ekonomi. Apalagi pada masa itu masih sangat sering, penduduk-penduduk dari wilayah yang kalah perang akan dijadikan budak. Persia tertarik kepada Yunani karena polis-polis di sana terutama Athena sukses di bidang perdagangan. Selain memanfaatkan penduduk menjadi budak, pengambil alihan di bidang ekonomi tentu menjadi tujuan utama negeri penakluk. 
Yunani mengetahui banyak tentang karakteristik Persia yang suka berperang dan pernahmenjadi sebuah imperium besar. Persia dan Yunani sudah saling mengenal satu sama lain meskipun interaksi keduanya lebih sering terjadi di medan pertempuran. Pengalaman Yunani bisa menjadi salah satu penyebab yang menginspirasi untuk mengadakan perluasan wilayah.

Keruntuhan Persia rupanya membuka peluang bagi Yunani yang sempat porak-poranda akibat perang saudara yang terjadi antara Athena dan Sparta. Kedua polis terkuat di Yunani pernah terlibat perang akibat ambisi masingmasing yang merasa lebih hebat. Bukan keuntungan yang didapat dari adanya pertikaian di dalam tubuh Yunani. Justru korban jiwa banyak yang berjatuhan. Namun, di sisi lain membuka peluang untuk Raja Philip II dari Kerajaan Makedonia yang bercita-cita menyatukan Yunani di bawah kekuasaannya untuk memperluas wilayah kerajaannya.

Orang-orang Sparta tinggal di bagian selatan wilayah Peloponesia. Mereka sangat menentang perpindahan ibu kota persekutuan dari Pulau Delos ke kota Athena, di wilayah Attica. Perang saudara Sparta-Athena yang lebih dikenal dengan nama Perang Peloponnesia diabadikan olehThucydides. la lahir antara tahun 470-460 SM di Athena. Pada tahun 424 SM, Thucydides diangkat menjadi jenderalperang tentara Athena untuk mempertahankan kota Amphipolis dari serangan pasukan Sparta. Amphipolisyang terletak di bagian timur laut Athena gagal dipertahankan oleh Thucydides. la diasingkan ke luarAthena selama kurang lebih 20 tahun sebagai hukuman atas kegagalannya,dan baru kembali ke Athena pada tahun404 SM setelah Athena dikalahkan Sparta. Thucydides memanfaatkan masa pembuangannya untuk menulissejarah Perang Peloponnesia (lbrahim, n.d.).

Berakhirnya Perang Peloponnesia membawa lembaran baru bagi Yunani dimana pada masa selanjutnya berada di bawah kepemimpinan raja Makedonia. Raja Philip berhasil menyatukan seluruh polis-polis di Yunani. Raja Philip memiliki keinginan kuat untuk melakukan perluasan wilayah kekuasaannya. Sayangnya, ia dibunuh saat masa kejayaannya. Waktu itu tentara Makedonia sudah tiba untuk menyerang Asia pada tahun 336 SM. Pasukan Yunani diambil alih oleh Alexander. la naik tahta karena memang sebelumnya telah menjabat sebagai raja muda. Meski masih tergolong muda, Alexander menunjukkan bahwa ambisinya lebih besar dibandingkan dengan ayahnya.

Alexander menyerang Persia menurut siasat yang sudah direncanakan ayahnya. Tahun 334 SM Alexander menyeberangi Selat Helespont dan membinasakan tentara Persia di tepi Sungai Granicus. Kemudian tentara Persia dapat dikalahkan lagi di sebelah utara Syria, sehingga ia dapat 
menguasai kota-kota Yunani di pantai Asia Barat. Sesudah mendapat kemenangan itu, Venesia dengan pelabuhan Sydon dan Tyrus, begitu pula Palestina diserang oleh Alexander. Sesudah mendapat serangan beberapa lamanya, kota Tyrus terpaksa menyerah atas perintah Alexander dan kota tersebut disamaratakan dengan tanah (Wirjosuparto, 1954).

Tahun 330 SM, pusat kekaisaran Persia dijatuhkan dan Makedonia memulai penaklukan di Iran Timur.Dalam tiga tahun yang luar biasa, Alexander dan pasukannya menjelajahi gunung-gunung Asia Tengah.Datang dari Kashmir, mereka menyusuri Sungai Jhelum menuju Rann Kutch (India sekarang). Pada tahun 323 SM, Alexander meninggal secara tiba-tiba dan tanpa disangka-sangka. Akibatnya keberhasilan politiknya meskipun sangat luar biasa, berakhir dengan buruk.Dua negara pengganti Kekaisaran Persia yang penting didirikan oleh dua perwira Alexander, yaitu Ptolomeus dan Seleucus. Ptolomeus memperoleh Mesir dan separoh daerah Selatan Syria. Seleucus memperoleh daerah terpenting, semua sisa daerah warisan Kekaisaran Persia (Ashadi, 2016).

Penduduk Persia dan daerah sekitar yang pernah masuk ke dalam imperiumnya harus beradaptasi kembali pada kebudayaan dan pola kepemimpinan baru yang berkiblat dari Yunani. Beberapa penduduk yang pernah menjadi tentara Persia dan ikut menyerang Yunani pasti telah mengetahui tentang cara hidup orang Yunani. Namun, bagi penduduk sipil yang tidak pernah terlibat perang akan merasa asing dengan suasana yang dibangun oleh pemerintah baru beserta kebudayaan yang dibawanya. Apalagi tentara perang Alexander The Great juga butuh logistik untuk persiapan invasi hingga sampai ke India. Harta rampasan perang dari Yunani hingga sampai ke India tentunya menjadi sponsor utama.

Masa kejayaan Alexander Yang Agung, sistem pemerintahan "City-State" mulai ditinggalkan dalam sistem ketatanegaraan dan berganti dengan sistem kerajaan. Kaisar Alexander dikenal sebagai raja yang gencar berperang. Karya seni di Yunani kurang mendapat perhatian dalam pemerintahannya. Pada masa ini ditandai dengan lahirnya filsuf-filsuf Yunani yang ajarannya kemudian menjadi panutan bangsanya (bahkan dunia). Mereka antara lain Socrates, Plato dan Aristoteles yang banyak memberi sumbangan-sumbangan besar dalam membentuk kepribadian bangsanya (Rahman, 2003).

Sejak muda putra mahkota dari Kerajaan Makedonia ini memang telah menunjukkan kemampuan yang baik dan genius. Alexander adalah cucu dari Raja Epirus. Ibunya bernama Olympias yang terkenal sebagai putri cantik jelita, tetapi memiliki kebiasaan aneh. Kehebatan Alexander kecil terlihat ketika ia mampu menaklukkan kuda liar dan beringas bernama Bucephalus. 
Kuda yang kuat dan gagah itu bahkan sulit dijinakkan oleh para perwira Raja Philip II. Namun, Alexander mampu menaiki kuda tersebut dan membawanya sebagai teman setia dalam perjalannya menuju Asia.

Alexander The Great memulai karirnya sebagai raja di usia muda dan memanfaatkan posisinya untuk melakukan invasi ke wilayah-wilayah yang sudah memiliki peradaban tinggi. Daerah taklukan Alexander meliputi Mesir, imperium Persia, India, dan lain-lain. Peradaban tinggi di Mesir dengan kebudayaannya yang khas telah dikenal sejak ribuan tahun sebelum masehi. Mesir dipimpin oleh Fir'aun yang membangun piramida dengan Spinx dan sistem pemerintahan yang kuat. Perang yang dilakukan Alexander ternyata banyak mendapatkan keberuntungan.

Kemenangan demi kemenangan yang diraih Alexander dan pasukannya ikut pula menyebarluaskan Peradaban Hellenis ke wilayah-wilayah yang ditaklukkan.Mereka menyebarkan peradaban itu dalam dengan sengaja secara luas ke daerah yang dikuasai. Selama selang waktu empat abad sebelum ekspedisi Alexander ke Timur, generasi awal Hellenis telah membukakan jalan mengunjungi Syria dan Mesir sebagai pedagang, mengabdi di Mesir danBabilonia serta Kekaisaran Persia sebagai prajurit bayaran (Ashadi, 2016).

Imperium yang dipimpin oleh Alexander dengan kerja keras dan penuh tantangan serta kelelahan para prajuritnya ternyata tidak mampu bertahan lama. Banyak dugaan yang muncul atas kematiannya yang mendadak. Beberapa orang menduga bahwa pemimpin besar Yunani itu sengaja diracuni agar tahta kerajaan bisa diambil alih. Namun, dugaan lain menyebutkan bahwa Alexander terkena panah tepat di dadanya saat akan kembali ke negara asalnya. Daerah taklukannya di timur maupun di barat terpecah-pecah menjadi kerajaan-kerajaan Hellenistik.

Invasi yang dilakukan Alexander dan pembentukan kerajaan Hellenis menyebabkan hilangnya batas-batas yang telah lama memisahkan Eropa dan Asia. Oleh sebab itu Timur Dekat menjadi terbuka bagi pedagang, tukang batu, tukang kayu, filsuf, ilmuwan, dan penulis Yunani. Akibatnya, oriental yang luas, tidak aktif, dan tidak progresif mengikuti aktifitas orang-orang Hellas. Mereka membawa kebudayaan Hellenis dan menjadi guru bagi orangorang di luar Yunani (Webster, 2017).

Keunggulan peradaban Hellenis juga dipengaruhi oleh pesatnya perkembangan ilmu pengetahuan serta kecintaan terhadap karya sastra. Bukubuku karya para filsuf di Yunani dipelajari. Alexander memberi kesan baik tentang kepeduliannya terhadap ilmu dan pelestarian buku-buku. Buktinya, setelah Mesir menyatakan takluk kepada Yunani, Alexander The Great 
mendirikan sebuah perpustakaan di daerah Alexandria. Fungsi perpustakaan sebagai penyimpanan buku-buku, dokumen-dokumen, dan karya sastra ternama yang mempengaruhi persebaran ilmu pengetahuan yang telah diteliti oleh para filsuf dari Yunani hingga ke kawasan Mesir. Kebudayaan Hellenis yang tersebar di Persia, Mesir dan India tentunya akan bersinggungan dengan kebudayaan asli yang telah ada sebelumnya. Penerapannya tergantung pada masyarakat yang mengadopsi budaya baru dengan budaya lama. Akulturasi mungkin terjadi pada daerah bekas taklukan perang.

\section{Simpulan}

Polis-polis di Yunani memegang peranan penting dalam pembentukan peradaban di Yunani. Sejak masa kuno dua polis ternama seperti Athena dan Sparta sudah menghiasi panggung politik dan sejarah Yunani. Keduanya memiliki ciri khas yang berlawanan. Penduduk yang mendiami dua polis tersebut menjadi orang-orang yang berpengaruh bagi polis-polis lainnya yang tersebar di seluruh Yunani.

Sparta terkenal dengan sistem militer yang mereka agungkan dan lebih mementingkan kekuatan fisik sehingga kebugaran jasmani begitu diperhatikan. Sistem pertahanan keamanan Sparta kuat dan ditakuti oleh polis-polis lain di sekitarnya. Anak laki-laki dilatih bertarung dan bertahan dalam kondisi yang sulit sejak usia dini. Saat memasuki usia dewasa penduduk laki-laki Sparta harus siap berlaga di medan pertempuran. Wilayah Sparta sering mendapat serangan dari luar.

Athena memiliki kecenderungan menonjol di bidang perkembangan seni dan ilmu pengetahuan. Penduduknya suka dengan keindahan sehingga banyak terdapat pahatan, lukisan-lukisan, taman-taman kota, dan pembangunan kuil yang megah. Sistem politik yang berlaku di bidang pemerintahan Athena menganut sistem demokrasi. Hal ini menunjukkan bahwa penduduk polis Athena sama sekali berbeda dengan karakter dengan penduduk Sparta. Pengaruh kebudayaan yang berkembang di Athena juga ikut berandil besar dalam pembentukan identitas peradaban Yunani.

Imperium Persia yang memiliki daerah taklukan luas di sekitar Babylonia, Asyiria, dan bangsa-bangsa lainnya mulai berambisi melakukan invasi dengan jalan peperangan ke kawasan Yunani. Saat Darius Agung memerintah, serangan ke Yunani sangat gencar. Perang antara Persia dan Yunani bahkan terjadi lebih dari tiga kali. Yunani merupakan daerah yang potensial untuk ditundukkan mengingat kesuksesan perdagangan yang diraih oleh penduduk Athena serta tingginya peradaban yang didukung oleh kemunculan para filsuf-filsuf ternama semakin menarik perhatian Persia kepada Yunani. 
Kontak fisik yang terjadi antara Yunani dan Persia masih berlanjut saat polis-polis di Yunani terlibat perang saudara. Polis paling kuat waktu adalah Sparta yang berperang melawan Athena sehingga disebut dengan Perang Peloponnesia. Bersamaan dengan kekalahan Athena, muncul seorang raja dari Makedonia bernama Philip II yang berhasil mengambil alih kepemimpinan di seluruh Yunani. Raja Philip memiliki cita-cita untuk menyatukan seluruh Yunani dan melakukan invasi ke daerah luar. Sayangnya, sanga raja dibunuh sehingga kepemimpinan beralih pada putranya.

Alexander the Great meneruskan cita-cita ayahnya untuk melakukan invasi keluar dari Yunani. Ambisinya lebih besar dan keinginan menundukkan kawasan Asia segera terlaksana. Tentara Yunani aktif menyerang daerah Iran yang merupakan tempat berdirinya Imperium Persia. Perang antara Yunani dan Persia dimenangkan oleh Yunani. Invasi ke Persia tentunya memberi keuntungan bagi pasukan Alexander. Kejatuhan Persia memberi tambahan energi bagi Alexander the Great untuk melanjutkan invasi ke India.

Invasi ke Persia oleh tentara Yunani meninggalkan kebudayaan baru bagi daerah taklukan untuk mengenal kebudayaan Hellenis. Tujuan dari invasi yang dilakukan oleh Alexander the Great selain untuk mempeluas daerah taklukan juga untuk menyebarkan peradaban dan kebudayaan Yunani. Kebudayaan Hellenis sebenarnya lebih banyak berkiblat pada kebudayaan Yunani. Sebab orang-orang Hellas memiliki kebebasan untuk menjamah kawasan taklukan Alexander. Kemegahan bangunan yang dihias dengan berbagai macam hasil karya seni menjadikan tempat-tempat di Athena lebih indah. Selain itu perhatian bagi perkembangan ilmu pengetahuan menempati posisi yang tinggi. Sebab, para filsuf terdahulu dari Yunani sangat mempengaruhi pola kepemimpinan dari Alexander the Great.

\section{Daftar Rujukan}

Ashadi, A. (2016). Peradaban dan Arsitektur Klasik Yunani-Romawi. Jakarta: Arsitektur UMJ Press.

Bertens, K. (1975). Sejarah Filsafat Yunani: Dari Thales ke Aristoteles. Yogyakarta: Kanisius.

Delfgauw, B. (1992). Sejarah Ringkas Filsafat Barat, terj. In Soejono Soemargono. Yogyakarta: Tiara Wacana Yogya. Yogyakarta: Tiara Wacana.

Hadiwijono, H. (1980). Sari sejarah filsafat barat. Yogyakarta: Kanisius. Ibrahim, M. Y. dan M. H. (n.d.). Sejarawan dan Pensejarahan: Ketokohan dan Karyanya. Kuala Lumpur: Dewan Bahasa dan Pustaka Kementrian Pendidikan Malaysia.

Muhammad Hatta. (1986). Alam Pikir Yunan. Yogyakarta: Kanisius.

Rahman, N. V. (2003). Menelusuri Jejak, Hubungan Dan Perbandingan Dua 
Kebudayaan Klasik, Yunani Dan Romawi. USU: Digital Library.

Rapar, J. . (1998). Filsafat Politik Plato. Jakarta: Rajawali.

Septianingrum, anisa. (2017). Sejarah Peradaban Dunia Kuno: Empat Benua. Yogyakarta: Sociality.

Sondranika, W. n. (2015). Peradaban Yunani Kuno. Jurnal Artefak, 3(2), 195206.

Stewart, E. (1995). The Heritage of the Past: From the Earliest Times to the Close of the Middle Ages. New York: Holt, Rinehart.

Sudrajat. (2010). Yunani Sebagai Icon Peradaban Barat. Istoria, 8(1), 11-29.

Sudrajat, A., \& Miftahuddin, M. A. (2008). Pengantar Sejarah Asia Barat Jurusan Pendidikan Sejarah Fakultas IImu Sosial Dan Ekonomi Universitas Negeri Yogyakarta 2008 Diktat Sejarah Asia Barat. Yokyakarta: Jurusan Pendidikan Sejarah FIS UNY.

Toynbee, A. J. (2004). Sejarah Umat Manusia. Yogyakarta: Tiara Wacana. Webster, H. (2017). Sejarah Dunia Lengkap. Yokyakarta: Indoliterasi.

Wirjosuparto, S. (1954). Sedjarah Dunia. Jakarta: Kementrian Pendidikan, Pengajaran dan Kebudayaan. 